\title{
Dynamic Model and Simulation of a MW-class Variable Speed Constant Frequency Doubly-Fed Wind Turbine Generator System
}

\author{
Shaobo Li \\ Key Laboratory of Advanced Manufacturing Technology, \\ Ministry of Education \\ Guizhou University \\ Guiyang, China
}

Jie $\mathrm{Hu}^{*}$

Key Laboratory of Advanced Manufacturing Technology, Ministry of Education

Guizhou University

Guiyang, China

*Corresponding author

\author{
Wanxia Wang \\ Key Laboratory of Advanced Manufacturing Technology, \\ Ministry of Education \\ Guizhou University \\ Guiyang, China \\ Guanci Yang \\ Key Laboratory of Advanced Manufacturing Technology, \\ Ministry of Education \\ Guizhou University \\ Guiyang, China
}

\begin{abstract}
By using Matlab/Simulink as a development and simulation platform, a wind turbine simulation-testing system was designed with the data from GH Bladed software and IEC61400-1 standard. Moreover, a whole dynamic model of a MW-class variable speed constant frequency Doubly-Fed wind generator is presented, including wind regime, drive train and inverter generator system. Furthermore, with the simulationtesting, closed-loop test and comprehensive dynamic test of control system can be realized. In the end, the experimental results illustrate the validity and feasibility of the system and it will provide a new way for wind turbine simulation and testing.
\end{abstract}

Keywords-component; wind turbine simulation; tip-speed ratio; wind energy utilization coefficient; drivetrain

\section{INTRODUCTION}

Wind turbine is multivariable, strongly coupled nonlinear system. At present, simulation test software for wind turbines large equipment is scarce at home and abroad. The foreign test software of the few has not been widely used in the domestic because of the expensive and lack of openness. In the process of simulation test research of wind generator, choosing Simulink as a development platform, which provide Convenient, intuitive, interactive graphical integrated simulation environment for design, manufacturing and control strategy of development of wind turbine. This platform with good economy and practicability don't need to be verified all of the tests at the scene of wind field. It greatly improves work efficiency.

By using Matlab/Simulink as a development and simulation platform, a wind turbine simulation-testing system was designed with the data from GH Bladed software and IEC61400-1 standard. Through the simulation test of a certain type wind generator, this system verify the effectiveness and availability of the wind turbine simulation test system. It supply a new way for professional simulation test of wind generator equipment.

\section{Simulation Modeling}

\section{A. Wind Energy Capture}

Wind power generation system is composed of mechanical parts and electrical energy conversion parts. By the aerodynamic characteristics theory, mechanical power per unit time is:

$$
\mathrm{P}=\frac{1}{2} \times \mathrm{C}_{\mathrm{p}} \times \rho \times \mathrm{A} \times \mathrm{v}^{3}
$$

(P- actual power; $\boldsymbol{\rho}$ - air density; $\boldsymbol{A}$ - rotor swept area; v - the wind speed; $\boldsymbol{C}_{\boldsymbol{p}}$-coefficient of wind energy capture)

\section{B. Tip Speed Ratio}

The ratio of the tip circumferential velocity and the wind speed is use to describe the speed of rotor velocity. The ratio is referred to as Tip speed ratio $\lambda$ :

$$
\lambda=\frac{2 \pi \times \mathrm{R} \times \mathrm{Ws}}{60 \times \mathrm{V}}
$$

(Ws-the speed of the wind turbines; R- rotor radius; v- the wind speed)

\section{Coefficient of Wind Energy Capture}

Coefficient of wind energy capture is defined as:

$$
C_{p}=\frac{P}{P_{w}}
$$


In the formula, $\mathrm{P}_{\mathrm{w}}$ is all the energy flows through the fan. Based on the approximate calculation, reasoning out a formula:

$$
C_{p}=(0.44-0.0167 \beta) \sin \left[\frac{\pi(\lambda-3)}{15-0.3 \beta}\right]-0.00184(\lambda-3) \beta(4)
$$

\section{( $\beta$-pitch angle of blade)}

Using Matlab draw a chart to show the relationship among $C_{p} 、 \lambda 、 \beta$. As shown in the figure I:

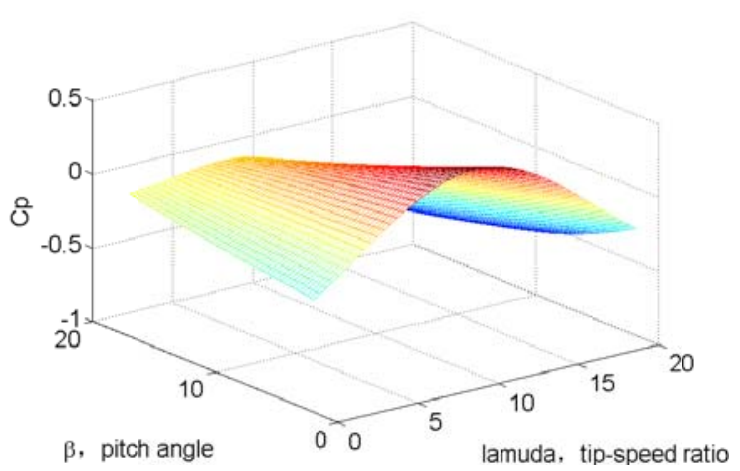

FIGURE I. WIND TURBINE CAPTURE COEFFICIENT CURVE

Theideal maximum of $\mathrm{C}_{\mathrm{p}}$ is 0.593 , according to Betz Limit. The greater the $C_{p}$, The greater the wind turbines can obtain the more energy from nature, namely the wind energy utilization is higher.

\section{Transmission Chain Model}

The figure II is the Schematic diagram of turbine's transmission chain:

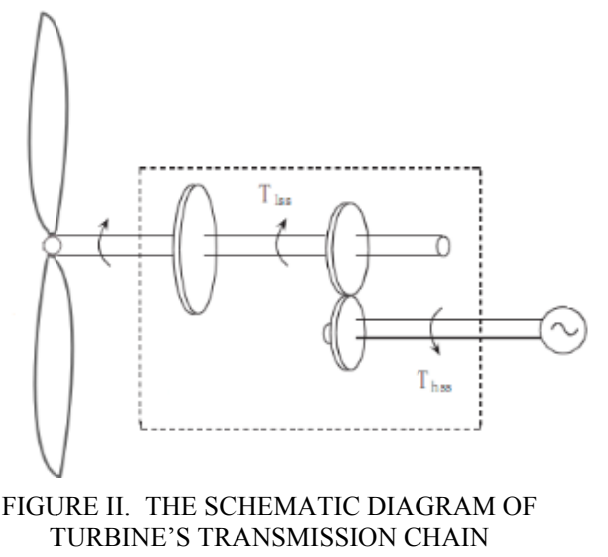

By dynamics analysis, ignoring the stiffness factor and damping factor of the principal axis of rotation, actual power in the formula (1) subtract electromagnetic power of the generator, transmission chain consumed power and mechanical brake power get the transmission chain drive power of the fan:

$$
P_{d}=P-P_{m}-P_{b r}-P_{c}
$$

Combined with the transmission chain's conservation of energy, there is a new formula after the discrete derivation:

$$
\mathrm{P}_{\mathrm{d}} \times \Delta \mathrm{t}=\frac{1}{2} \mathrm{~J} \omega_{1}^{2}-\frac{1}{2} \mathrm{~J} \omega_{2}^{2}
$$

( $\Delta \mathrm{t}$-the time step, cycle-time of the running program on the PLC; J-moment of inertia of transmission chain; $\omega_{1} 、 \omega_{2}$ are the angular velocity before and after the period respectively)

Getting the following formula after deformation, by exchange the angular velocity into the speed of the wind turbines:

$$
\mathrm{W}_{1}=\sqrt{\frac{182.56 \times \mathrm{P}_{\mathrm{d}} \times \Delta \mathrm{t}}{\mathrm{J}}+\mathrm{W}_{2}^{2}}
$$

$\mathrm{W}_{1} 、 \mathrm{~W}_{2}$ are the speed of the wind turbines before and after the period respectively, which are the final output from transmission chain model.

\section{E. Wind Turbines Model}

Modular modeling can realize more flexible simulation, and easier to extend. Splited up wind turbines simulation model into several modules as the tableI:

TABLE I. SimULATION OF WIND TURBINES' MODULES

\begin{tabular}{|c|c|}
\hline $\begin{array}{c}\text { Wind regime } \\
\text { module }\end{array}$ & $\begin{array}{c}\text { IEC wind model and TurbSim turbulent } \\
\text { wind model. }\end{array}$ \\
\hline $\begin{array}{c}\text { Wind turbines pneumatic } \\
\text { module }\end{array}$ & $\begin{array}{c}\text { Combined with Simulink and Bladed to set } \\
\text { fan wheel's radius. Through the tip speed } \\
\text { ratio and pitch angle to solve the coefficient } \\
\text { of wind energy capture. }\end{array}$ \\
\hline $\begin{array}{c}\text { Transmission chain } \\
\text { module }\end{array}$ & $\begin{array}{c}\text { To establish a mathematical } \\
\text { modeltransmitting torque's dynamic } \\
\text { response. It will reflect energy loss of } \\
\text { transmission chain, and couple with power } \\
\text { converter systems. }\end{array}$ \\
\hline $\begin{array}{c}\text { Variable pitch system } \\
\text { module }\end{array}$ & $\begin{array}{c}\text { Building a variable pitch actuator model by } \\
\text { using Matlab/Simulink, for monitoring of the } \\
\text { set value }\end{array}$ \\
\hline $\begin{array}{c}\text { Power inverter } \\
\text { module }\end{array}$ & $\begin{array}{c}\text { By using Matlab/Simulink to achieve the } \\
\text { precise modeling for complex generator and } \\
\text { inverter. }\end{array}$ \\
\hline
\end{tabular}

The model adopts a three bladed horizontal axis wind turbine, and the air density is $1.255 \mathrm{~kg} / \mathrm{m}^{3}$. By using Matlab/Simulink to build a closed-loop model of transmission chain as follow figure III:

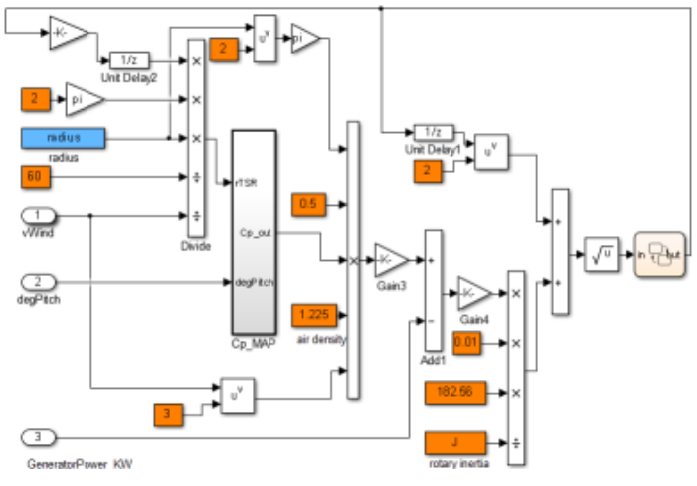

FIGURE III. A CLOSED-LOOP MODEL OF TRANSMISSION CHAIN 


\section{Wind Turbines SimUlation Test System}

\section{A. The Simulation Test System}

Based on Matlab/Simulink platform, the simulation test system use GH Blade software data, IEC wind data and related model put forward by the above, to realize integratedsimulation of wind energy conversion system and testing of system interconnection, control strategy, and other functions. Then, the system's data will dock with the fan controller. Simulation system is set up as shown in figure IV:

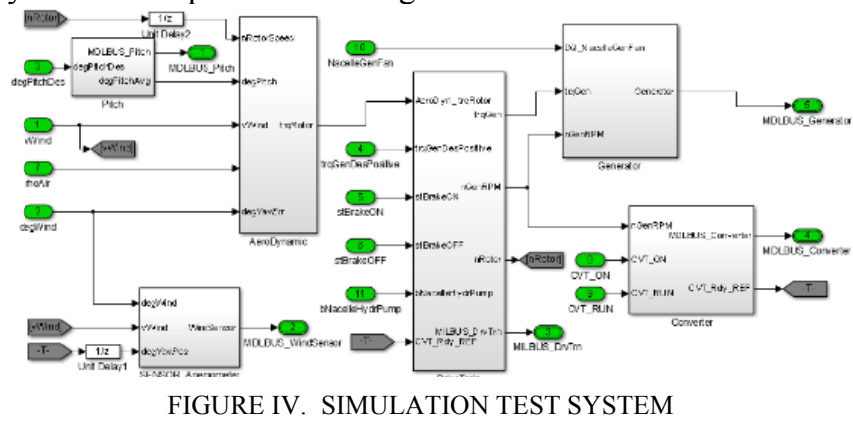

\section{B. Simulation Function}

According to the different modules, the whole simulation platform is introduced as follow:

1) Wind regime module is used to simulate the actual wind speed and the signal of wind direction. As the main input conditions of wind turbines, the simulation of turbulent intensity not only can be more real reaction wind speed changes, but also provide more accurate basis for design and manufacturing of the machine. Moreover, opening external writable interface is able to reproduce the scene by using the data recorded.

2) Wind turbines pneumatic module and transmission chain module as shown in figure 3 , main parts of transmission chain, like main shaft, gear box, etc. It can set parameters such as gearbox ratio, transmission efficiency and shaft rotational inertia, and couple with wind regime module, pitch system module and power inverter module. The algorithm design has been detailed above.

3) Variable pitch system module is used to simulate the actual variable pitch actuator. According to the pitch Angle from the controller, it will change the blade angle. At the same time, angle encoder feedback real value. The set adopt the firstorder time-delay system.

4) Power inverter module simulates core components-generator and inverter. The two respond cutting-in, cutting-out control, and power setting command, esc, to achieve energy conversion and adjust the equipment operation.

\section{Test Function}

After completing the system, pursuant to the conditions of the IEC 61400-1 and recording condition at the wind field, the following test project is carried out.

\section{1) Start and stop of the unit}

This system will verify whether the control system can correct control unit or not under different turbulent wind speed, and whether it can activate outage protection after fault and the wind does not meet the requirements.

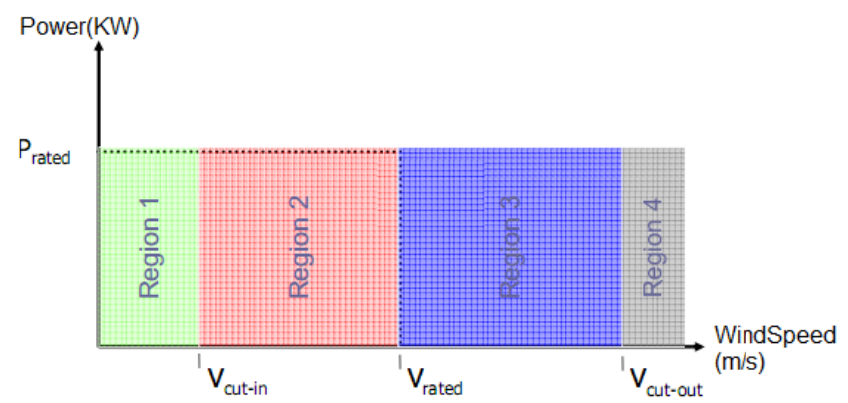

FIGURE V. FOUR WIND SPEED CONTROL RANGE

\section{2) Cutting-in and cutting-out functions}

Under the condition meeting grid-connection requirements, it will verify issued instructions and responses from controller, inverter and the generator, and the cooperation between inverter and generator. When can't continue to grid-connection, the system also verify whether it could cut out safely and smoothly.

3) Variable speed constant frequency control and variable pitch control function

For variable speed and paddle wind turbines, the control strategy can be divided into four control range in different wind speed. As shown in figure 5, some test about the change of the blade, speed, etc, will be carried out in each region.

Region 1: Gentle wind area. Variable pitch is downtime. Speed and torque don't be given.

Region 2: wind speed is between [ $\left.\mathrm{v}_{\text {cut-in }}, \mathrm{v}_{\text {rated }}\right]$. Generator speed is lower than the rated speed.

Region 3: wind speed is between $\left[\mathrm{v}_{\text {rated }}, \mathrm{v}_{\text {cut-out }}\right]$. After speed reach the rated speed, variable pitch control should be taken to keep speed of the unit, for keeping rated output power.

Region 4: Strong wind area. Although the system is easy to get full output, it has been seriously affect the safe operation of unit. So, the fan in this area is in the down state.

\section{4) Real-time monitoring function}

The wind regime, fault and combination condition will be set in the process of testing, to verify real-time monitoring mechanism and treatment measures of the control system. The more you consider, the less time and cost for testing will be spent.

\section{EXPERIMENTAL VERIFICATION}

\section{A. The Simulation Object}

The model of system parameters, of which one well-known domestic wind turbine manufacturers, is inputted to the wind turbine simulation platform, to realize the simulation test and results. 
TABLE II. Wind POWER System PARAmeters

\begin{tabular}{|l|l|}
\hline parameter & value \\
\hline R- rotor radius & $44 \mathrm{~m}$ \\
\hline $\boldsymbol{\rho}$ - air density & $1.255 \mathrm{~kg} / \mathrm{m}^{3}$ \\
\hline $\boldsymbol{P}_{\text {rated }}$-rated power & $1.5 \mathrm{MW}$ \\
\hline $\boldsymbol{v}_{\text {cut-in}}$-cut in wind speed & $3 \mathrm{~m} / \mathrm{s}$ \\
\hline $\boldsymbol{v}_{\text {cut-out}}$-cut out wind speed & $25 \mathrm{~m} / \mathrm{s}$ \\
\hline $\boldsymbol{v}_{\text {rated }}$-reated wind speed & $13 \mathrm{~m} / \mathrm{s}$ \\
\hline Ratio-gearbox ratios & $1: 104$ \\
\hline $\boldsymbol{\mu}$-transmission efficiency & $95 \%$ \\
\hline Low speed shaft rotational inertia & $120000 \mathrm{~kg} \cdot \mathrm{m}^{2}$ \\
\hline High-speed shaft rotational inertia & $550 \mathrm{~kg} \cdot \mathrm{m}^{2}$ \\
\hline generator rated speed & $1800 \mathrm{rpm}$ \\
\hline
\end{tabular}

\section{B. Simulation Implementation and the Result Analysis}

Simulation with turbulent wind conditions, wind speed fromv $v_{\text {cut-in }}$ gradually rise to $\mathrm{v}_{\text {rated }}$. The whole process of wind turbines is shown in figure 6. Blade Angle constantly decreases, the generator speed rise, until the value is 1800 RPM, achieving 1.5 MW full load output. At the same time, it will complete the start-up of the unit, speed control and verify controlling for grid-connected.

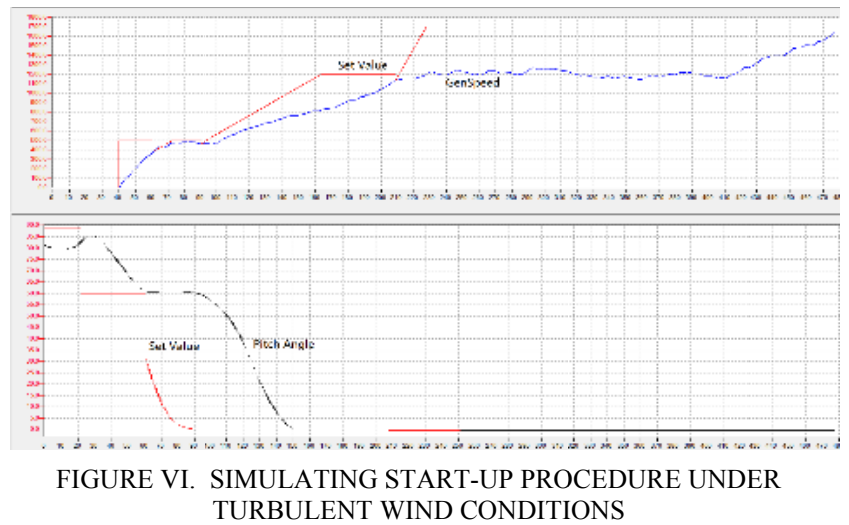

Figure VII shows the recorded curve reflecting the process of start-up of the unit and grid-connected. It collects this wind turbine site operation data and wind conditions date, and inputs these data into the simulation test system to comparing the simulation with the real machine running effect.

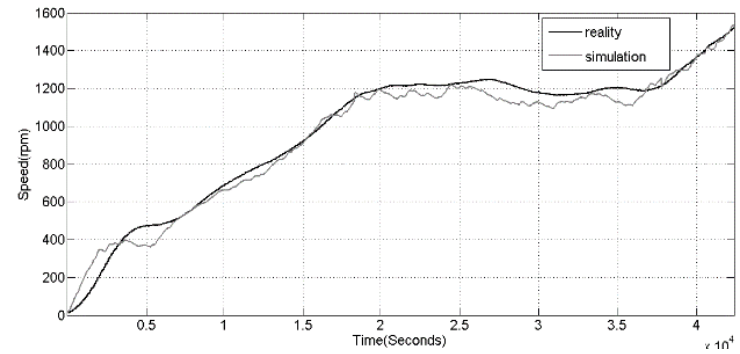

FIGURE VII. THE SIMULATION AND MEMOIR SPEED CURVE

As you can see in figure VII, the simulation curve is nearly close to the field operation curve. It shows that this paper demonstrates that the proposed method and the development of testing system are effective. However, by comparing the curve, we can find that the simulation speed fluctuation is bigger, slightly lower than the real machine speed as a whole. The wind speed from the field is 1 millisecond, so the simulation system adopted the turbulent coefficient interpolation method In order to obtain 10 millisecond real-time input speed of operation cycle. That's why the wind velocity mutation is bigger. As shown in figure VIII, mutation of wind caused the speed fluctuation. When the turbulence intensity is reduced, the simulation speed curve is smooth.

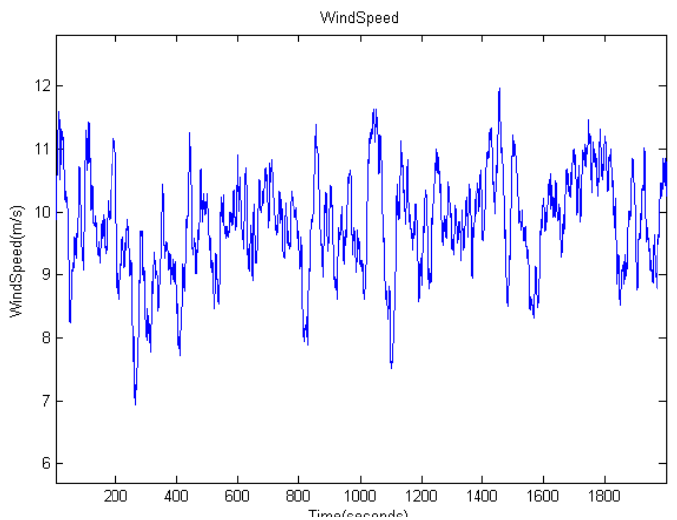

FIGURE VIII. AFTER THE INTERPOLATION OF WIND SPEED WAVEFORM

In addition, on-site anemometer is mounted behind turbine, the recorded data is actually after wind turbines to absorb energy reduction of wind speed, so the speed slightly higher is reasonable. After corrected the speed in the simulation system, the two curves are more closed to each other.

\section{CONCLUSION}

Wind power has very important significance for improving energy efficiency, improve the energy structure, the development of low carbon economy. In addition, the development of wind turbine simulation test system has important scientific significance and engineering application value to speed up design and manufacturing of the wind turbines. It is presented in this paper that a wind power system simulation model and the method and realization of the development of the test system. With the mature commercial software data and real data of wind turbine to verify the effectiveness and availability of the wind turbine simulation test system, it is provides a new way for large wind power generator equipment professional simulation test, can provide a reference for relevant engineering applications.

\section{ACKNOWLEDGMENT}

This research is supported by the National Natural Science Foundation of China under Grant 51475097, Project of National Science and Technology Support under Grant 2012BAF12B14, Key Project of Guizhou Province Science and Technology under Grant JZ-[2014]2001.

\section{REFERENCES}

[1] Tony Burton. Wind Energy Handbook, 2nd edition [M]. Beijing, Science and Technology Press.2014. 
[2] HUANG Xin; SUN Yan-bin. A Research on Hierarchy of Wind Power System Simulation Technique [J]. Journal of Hubei University of Technology.2013,5: 102-110.

[3] ZHOU Ning, FU Lei, YANG Jia, YANG Hongtao, WEI Fenqing, Jiangxi. Test and Research Platform for DFIG System Based on Realtime Simulation [J]. Proceedings of the CSEE,2013, 37(S1) : 10-19.

[4] WANG Ming-dong, JIA De-feng, LV Meng-qi. Stateflow -based Design and Simulation for Master Control System of Wind Generating Set [J]. Journal of Zhengzhou University(Engineering Science), 2011, 32(2):114-116.

[5] IEC 61400-1, Wind turbines-Part 1: Design requirements[S]. IEC, 2010

[6] WU Ding-hui, JI Zhi-cheng. Design and Digital Controller For Wind Energy Conversation System Bases on dSPACE[J]. Small \& Special Electrical Machines, 2010(1):48-50.
[7] LIU Yu-shan, GE Bao-ming, BI Da-qiang, WANG Wen-Hang. Improved direct torque control based wind turbine simulation system [J]. Power System Protection and Control,2010,38(18) : 140-144.

[8] Jadhav K U, Thosar A G. Simulation for power generation related to variable wind speed using Matlab [J]. Proceedings of 2013 IEEE International Conference on Energy Efficient Technologies for Sustainability, 2013(1) :472-475.

[9] LI Xin, ZENG Ling-quan, HOU Bin, SHAN Fan. Analysis of the simulated windmill wind power generation system [J]. Journal of North China Electric Power University(Natural Science Edition), 2010,11(60):17-23.

[10] BABU B C, MOHANTY K B. Doubly-Fed Induction Generator for Variable Speed Wind Energy Conversion Systems- Modeling \& Simulation [J]. International Journal of Computer and Electrical Engineering,
2

(1):141-147 